\title{
Effect of Grain Boundary Modification on the Microstructure and Magnetic Properties of HDDR-treated Nd-Fe-B Powders
}

\author{
Shu Liu ${ }^{1,2}$, Nam-Hyun Kang ${ }^{2}$, Ji-Hun Yu ${ }^{1}$, Hae-Woong Kwon ${ }^{3}$, and Jung-Goo Lee ${ }^{1 *}$ \\ ${ }^{1}$ Powder \& Ceramics Division, Korea Institute of Materials Science, 797 Changwondaero, Changwon 51508, Korea \\ ${ }^{2}$ Department of Materials Science and Engineering, Pusan National University, Busandaehak-ro 63 beon-gil, \\ Geumjeong-gu, Busan 46241, Korea \\ ${ }^{3}$ Department of Materials Science and Engineering, Pukyong National University, Yongso-ro 45 Nam-gu,
} Busan 48513, Korea

(Received 31 December 2015, Received in final form 11 March 2016, Accepted 13 March 2016)

\begin{abstract}
The microstructure and magnetic properties of HDDR-treated powders after grain boundary diffusion process (GBDP) with $\mathrm{Nd}-\mathrm{Cu}$ alloy at different temperatures have been studied. The variation of GBDP temperature had multifaceted influences on the HDDR-treated powders involving the microstructure, phase composition and magnetic performance. An enhanced coercivity of $16.9 \mathrm{kOe}$ was obtained after GBDP at $700{ }^{\circ} \mathrm{C}$, due to the modified grain boundary with fine and continuous Nd-rich phase. However, GBDP at lower or higher temperature resulted in poor magnetic properties because of insufficient microstructural modification. Especially, the residual hydrogen induced phenomenon during GBDP strongly depended on the GBDP temperature.
\end{abstract}

Keywords : $\mathrm{Nd}-\mathrm{Fe}-\mathrm{B}$ magnets, $\mathrm{HDDR}, \mathrm{Nd}-\mathrm{Cu}$ alloy, residual hydrogen

\section{Introduction}

The Nd-Fe-B permanent magnets have been widely used as indispensable materials for various kinds of motors and actuators due to their excellent magnetic properties and cost performances [1]. Especially, high efficiency traction motors for hybrid electric vehicles (HEVs) or electric vehicles (EVs) is one of the most rapidly growing areas [2]. For these applications, higher coercivity than that required for other applications is needed to withstand the demagnetization problem at the high operation temperature of the motor $\left(\sim 200^{\circ} \mathrm{C}\right)$. The temperature coefficient of coercivity has a largely negative value; it means the coercivity decreases rapidly as the temperature increases, which is the main drawback of $\mathrm{Nd}-\mathrm{Fe}-\mathrm{B}$ magnets. In order to overcome this problem, one of the most effective solutions is doping heavy rare earth (HRE) element such as $\mathrm{Dy}$ or $\mathrm{Tb}$ into the $\mathrm{Nd}-\mathrm{Fe}-\mathrm{B}$ magnets, which cause the large coercivity enhancement at room temperature. However, the enhancement of coercivity by

CThe Korean Magnetics Society. All rights reserved.

*Corresponding author: Tel: +82-55-280-3606

Fax: +82-55-280-3289, e-mail: jglee36@kims.re.kr the doping of HRE elements can only be achieved at the expense of the maximum energy product, due to the reduction in the magnetization via the antiferromagnetic coupling between the magnetic moments of HRE elements and $\mathrm{Fe}$ element [3]. Moreover, the natural abundance of HRE elements is quite low and their material prices are unstable. Thus, achieving high coercivity without HRE elements is an urgent issue for high-temperature motor application of $\mathrm{Nd}-\mathrm{Fe}-\mathrm{B}$ permanent magnets. Intensive studies have been focused on producing high coercivity $\mathrm{Nd}-\mathrm{Fe}-\mathrm{B}$ magnets without HRE elements [4-6] and it is now well known that the coercivity is strongly influenced by the microstructures such as grain size and grain boundary (GB) [7-9]. With regard to the former, the coercivity increases with the decrease of grain size down to the single domain size $(\sim 250 \mathrm{~nm})$. The hydrogenation-disproportionation-desorption-recombination (HDDR) process is one of the most effective methods to produce anisotropic $\mathrm{Nd}-\mathrm{Fe}-\mathrm{B}$ magnetic powders with single domain-sized grains [10]. However, the reported highest coercivity of HDDR-treated $\mathrm{Nd}-\mathrm{Fe}-\mathrm{B}$ powders without HRE was disappointingly low considering from the ultrafine grain size [11]. The poor coercivity of HDDR-treated $\mathrm{Nd}-\mathrm{Fe}-\mathrm{B}$ powders with nearly single domain-sized 
grains is attributed to the insufficient control of the $\mathrm{Nd}-$ rich GB phase which is significantly important to induce magnetic decoupling between grains [12]. The magnetic decoupling is essential to enhance the coercivity of fine grained magnets [13]. Many studies have demonstrated that the addition of some alloy additives or trace elements, such as $\mathrm{Pr}, \mathrm{Cu}, \mathrm{Nd}, \mathrm{Al}$, and $\mathrm{Ga}$, can efficiently improve the coercivity [13-15]. In other words, the homogenous distribution of Nd-rich phase through the GBs among $\mathrm{Nd}_{2} \mathrm{Fe}_{14} \mathrm{~B}$ main phases can significantly increase the coercivity of fine-grained $\mathrm{Nd}-\mathrm{Fe}-\mathrm{B}$ magnets [16]. On the other hand, it is recently reported that HDDR-treated NdFe-B powders contain a significant amount of the residual hydrogen [17]. Matin et al. have found the coercivity of HDDR-treated Nd-Fe-B powders was significantly reduced after heat treatment due to the residual hydrogen [18]. However, there is no report on the effect of the residual hydrogen during grain boundary diffusion process (GBDP).

In the present work, GB phase of HDDR-treated Nd$\mathrm{Fe}-\mathrm{B}$ magnetic powders was modified by GBDP with $\mathrm{Nd}-\mathrm{Cu}$ alloy. The effect of GBDP with $\mathrm{Nd}-\mathrm{Cu}$ alloy on the microstructure and magnetic properties of HDDRtreated $\mathrm{Nd}-\mathrm{Fe}-\mathrm{B}$ powders has been studied. Furthermore, the temperature effect of $\mathrm{GB}$ modification with $\mathrm{Nd}-\mathrm{Cu}$ alloy on the phases and microstructures has been discussed.

\section{Experimental}

The starting powders with a normal composition of $\mathrm{Fe}_{80.4} \mathrm{Nd}_{12.5} \mathrm{~B}_{5.7} \mathrm{Nb}_{0.4} \mathrm{Ga}_{0.8} \mathrm{Co}_{0.2}$ (at.\%) were produced by the standard HDDR process [19]. The average particle size and grain size of the powders was $100 \mu \mathrm{m}$ and 300 $\mathrm{nm}$, respectively. The $\mathrm{Nd}_{70} \mathrm{Cu}_{30}$ (at.\%) alloy were arc melted to ingot and then melt-spun to ribbons, followed by vacuum ball milling to particle size of smaller than $4.5 \mu \mathrm{m}$. The $\mathrm{Nd}_{70} \mathrm{Cu}_{30}$ (at.\%) powders mixed with the HDDR-treated powders at mass fractions of $6 \%$. The mixed powders were then subjected to GBDP in vacuum at 600,700 and $800{ }^{\circ} \mathrm{C}$ for $3 \mathrm{~h}$, respectively. After that, the powders were quickly gas-quenched to room temperature (RT). The magnetic properties of the powders were measured by a vibrating sample magnetometer (VSM) at RT. For the VSM measurement, the powders mixed with paraffin were aligned and magnetized under $1.5 \mathrm{~T}$ static magnetic field and $5 \mathrm{~T}$ pulsing magnetic field, respectively. The microstructure and morphology of the powders were analyzed by powder X-ray diffraction (XRD), scanning electron microscopy (SEM) and transmission electron microscopy (TEM).

\section{Results and Discussion}

Figure 1 shows the SEM images of the initial HDDRtreated powders $(\mathrm{a}, \mathrm{b})$, and the powders after GBDP with 6 wt.\% $\mathrm{Nd}-\mathrm{Cu}$ alloy at $600{ }^{\circ} \mathrm{C}(\mathrm{c}, \mathrm{d}), 700^{\circ} \mathrm{C}(\mathrm{e}, \mathrm{f})$ and $800{ }^{\circ} \mathrm{C}(\mathrm{g}, \mathrm{h})$ for $3 \mathrm{~h}$, respectively. The SEM images of the fractured surface show that the grain size of the initial HDDR-treated powders is around $300 \pm 50 \mathrm{~nm}$ (Fig. 1(a)) and no significant change in the grain size was observed after GBDP at $600{ }^{\circ} \mathrm{C}$ (Fig. 1(c)) and $700{ }^{\circ} \mathrm{C}$ (Fig. 1(e)). It should be noted that $\mathrm{Nd}_{2} \mathrm{Fe}_{14} \mathrm{~B}$ grains are surrounded by thin GB layers (arrowed) after GBDP treatment at $700{ }^{\circ} \mathrm{C}$ as shown in Fig. 1(e). Further increase of the GBDP temperature up to $800{ }^{\circ} \mathrm{C}$, resulted in the grain growth up to $450 \pm 50 \mathrm{~nm}$. In the backscattered electrons (BSE) images, dark and bright contrast region corresponds to
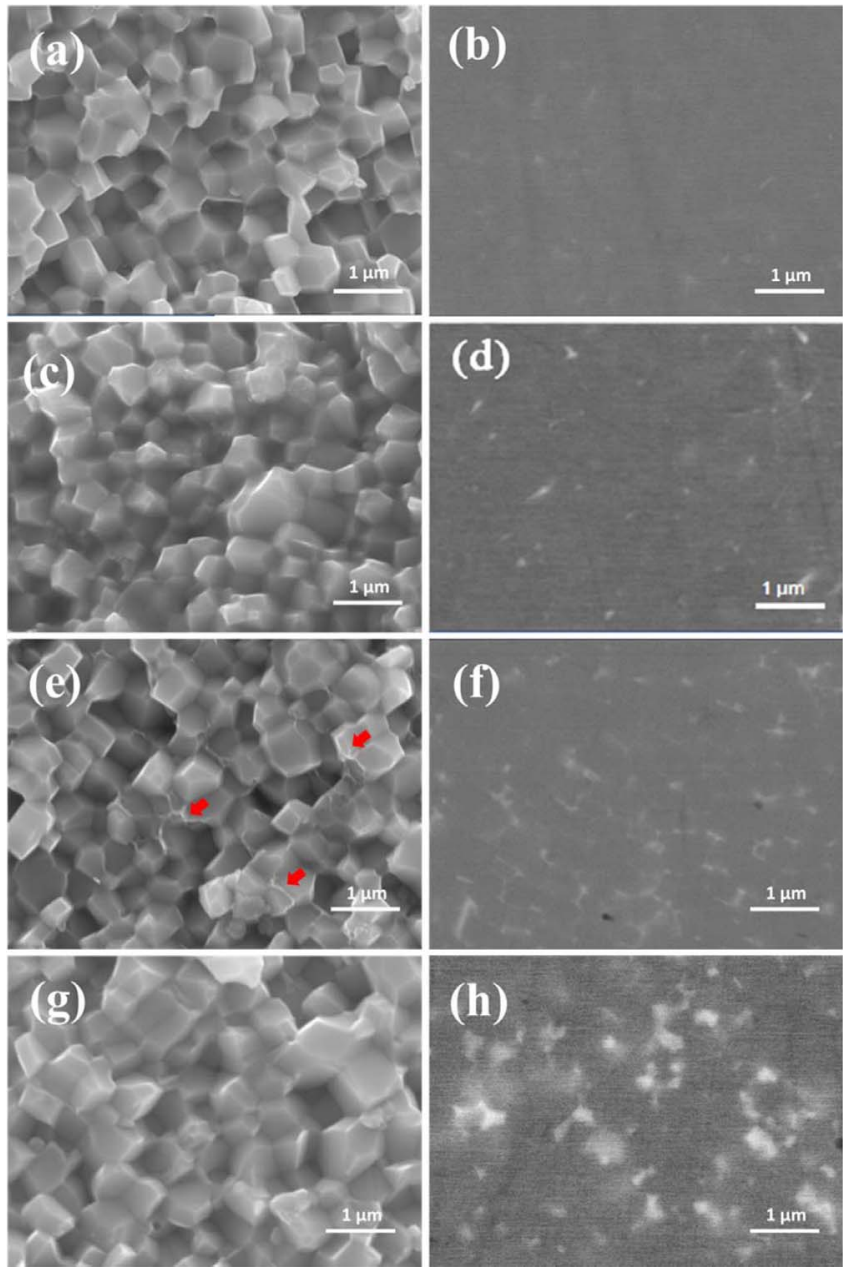

Fig. 1. (Color online) SEM images of the initial HDDRtreated powders, and the powders after GBDP with 6 wt.\% $\mathrm{Nd}-\mathrm{Cu}$ alloy at 600,700 and $800{ }^{\circ} \mathrm{C}$ for 3 hours, respectively. (a), (c), (e), (g) : SE mode image of the fractured surface, and (b), (d), (f), (h) : BSE mode image of the cross-section surface. 
$\mathrm{Nd}_{2} \mathrm{Fe}_{14} \mathrm{~B}$ main phase and Nd-rich GB phase, respectively. All samples consist of two contrast regions. However the relative fraction and distribution of the bright contrast area are different among the samples. It is quite difficult to find Nd-rich GB phase in the initial HDDR-treated powder (Fig. 1(b)). The bright region slightly increase but its distribution is not uniform after GBDP at $600{ }^{\circ} \mathrm{C}$ (Fig. 1(d)), which indicates that there is no significant enrichment of Nd-rich phase along the GBs. For the powders after GBDP at $700{ }^{\circ} \mathrm{C}$, the bright regions are much more uniformly distributed along the GBs as shown in Fig. 1(f), revealing that the Nd-rich phase is fine and uniformly distributed not only at the triple junction but also along the GBs. These microstructural features suggest that low melting point binary $\mathrm{Nd}-\mathrm{Cu}$ alloy melted and infiltrated into the HDDR-treated powders, and further induced the formation of $\mathrm{Nd}$-rich phase through the GBs during heat treatment. With further increase of GBDP temperature up to $800{ }^{\circ} \mathrm{C}$, the $\mathrm{Nd}$-rich phase aggregated to the triple junctions and became indistinguishable again along the GBs (Fig. 1(h)). The absence of Nd-rich phase at the GBs can lead to the magnetic coupling among the $\mathrm{Nd}_{2} \mathrm{Fe}_{14} \mathrm{~B}$ main phases [20].

Figure 2 shows the XRD patterns of the initial HDDRtreated powders and the powders after GBDP with $6 \mathrm{wt} . \%$ $\mathrm{Nd}-\mathrm{Cu}$ alloy at 600,700 and $800{ }^{\circ} \mathrm{C}$ for $3 \mathrm{~h}$, respectively. It can be clearly observed that the main characteristic peaks for all these samples correspond to the $\mathrm{Nd}_{2} \mathrm{Fe}_{14} \mathrm{~B}$ phase. It is interested to note that the diffraction peaks after GBDP at 600 and $800{ }^{\circ} \mathrm{C}$ were shifted toward higher angles compared with those of the initial HDDR-treated powder (Fig. 2(b)), which indicates that the lattice of the tetragonal $\mathrm{Nd}_{2} \mathrm{Fe}_{14} \mathrm{~B}$-type phase was shrunk after GBDP. Quite recently, it was reported that the HDDR-treated $\mathrm{Nd}-\mathrm{Fe}-\mathrm{B}$-type magnetic powders contained a significant amount of hydrogen in the form of $\mathrm{Nd}_{2} \mathrm{Fe}_{14} \mathrm{BH}_{\mathrm{x}}$ hydride, which would be disproportionate into $\alpha-\mathrm{Fe}, \mathrm{Fe}_{2} \mathrm{~B}$ and $\mathrm{NdH}_{2}$ phase during heat treatment above a threshold temperature [18]. So the lattice shrinkage in Fig. 2 can be attributed to the release of residual hydrogen from the HDDR-treated powders during GBDP. In addition, the peaks for the disproportionated phases of $\alpha-\mathrm{Fe}, \mathrm{Fe}_{2} \mathrm{~B}$ could be clearly confirmed after GBDP at 600 and 800 ${ }^{\circ} \mathrm{C}$, which indicates that degassing and disproportionation is a dominant phenomenon in the HDDR-treated powders during heat treatment at 600 and $800{ }^{\circ} \mathrm{C}$. This result is consistent with the fact that the threshold temperature for disproportionation is around $600{ }^{\circ} \mathrm{C}$ [21]. On the other hand, there is no shift of the diffraction peaks after GBDP at $700{ }^{\circ} \mathrm{C}$ compared with those of the initial HDDRtreated powder, and the $\mathrm{Fe}_{2} \mathrm{~B}$ was not detected.
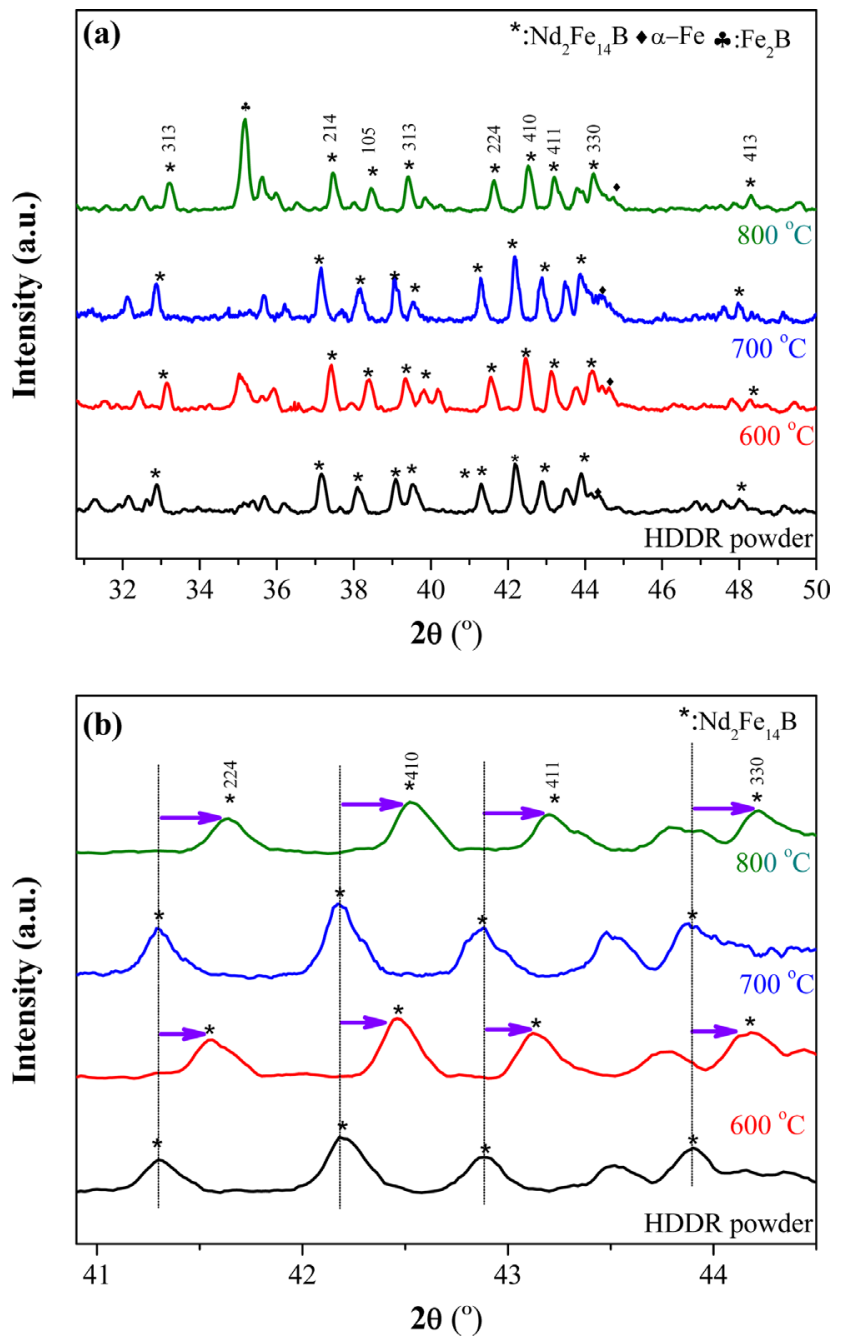

Fig. 2. (Color online) XRD patterns of the initial HDDRtreated powders and the powders after GBDP with 6 wt.\% $\mathrm{Nd}-\mathrm{Cu}$ alloy at 600,700 and $800{ }^{\circ} \mathrm{C}$ for 3 hours, respectively (b) enlarged view of angle shift.

More detailed microstructural observation was carried out using TEM. Figure 3 shows energy-filtered elemental mapping images and high-magnification bright field images of the powders after GBDP with $\mathrm{Nd}-\mathrm{Cu}$ alloy at $800^{\circ} \mathrm{C}$. It can be confirmed that the $\alpha-\mathrm{Fe}$ and $\mathrm{Fe}_{2} \mathrm{~B}$ phases were formed in the HDDR-treated powders after GBDP at $800{ }^{\circ} \mathrm{C}$ (Fig. 3(c) and (f)). This result is consistent with XRD result in Fig. 2.

From these results, it seems that the molten and diffused $\mathrm{Nd}-\mathrm{Cu}$ alloy along GBs play a role in not only isolating the main phase but also preventing degassing of hydrogen from the HDDR-treated powders. However, further studies are needed to get a deep understanding of the relationship between GBs and degassing of residual hydrogen from HDDR-treated powders. 

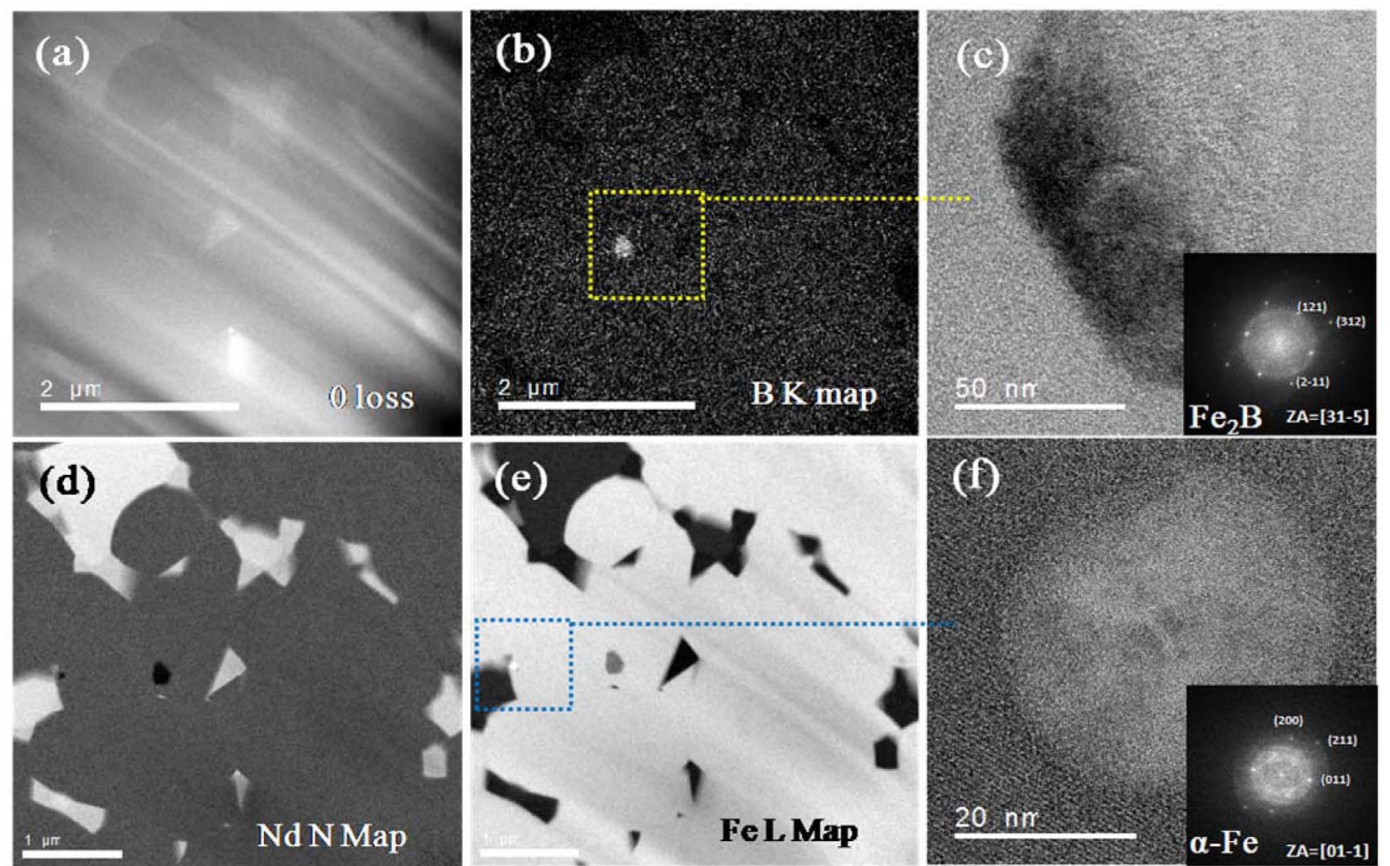

Fig. 3. (Color online) Energy filtered elemental mapping images and high-magnification bright field images of the HDDR-treated powder after GBDP with 6 wt.\% $\mathrm{Nd}-\mathrm{Cu}$ alloy at $800{ }^{\circ} \mathrm{C}$ using TEM.

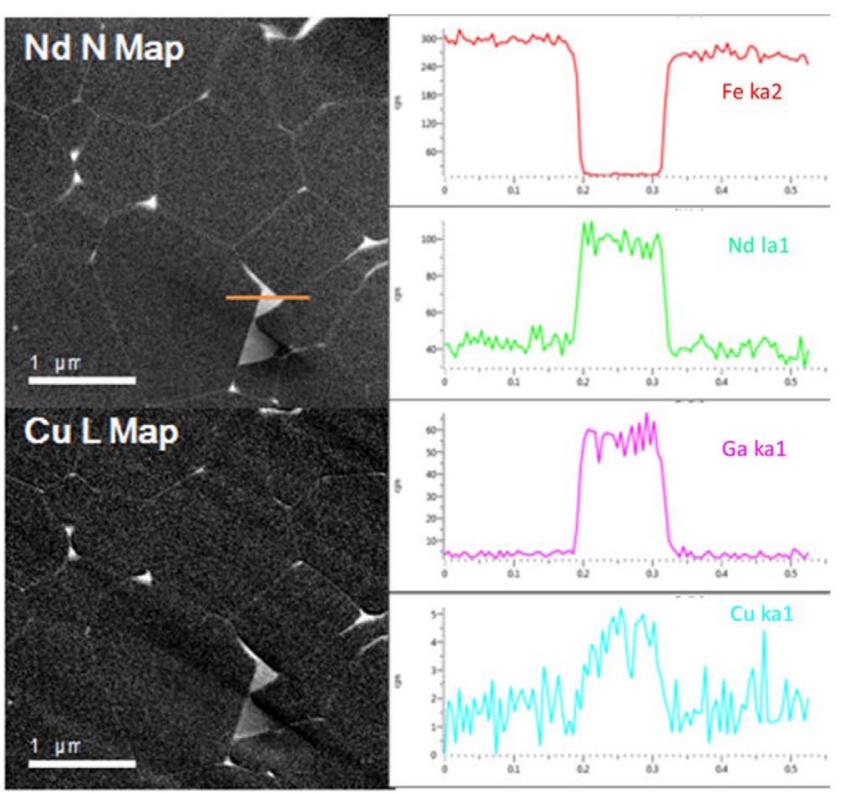

Fig. 4. (Color online) Elemental maps of $\mathrm{Nd}$ and $\mathrm{Cu}$ (left parts) and line scans (right parts) of the HDDR-treated powders after GBDP with 6 wt. $\% \mathrm{Nd}-\mathrm{Cu}$ alloy at $700{ }^{\circ} \mathrm{C}$.

Figure 4 shows elemental maps and line scans obtained using TEM for the HDDR-treated powders after GBDP with 6 wt. $\% \mathrm{Nd}-\mathrm{Cu}$ alloy at $700{ }^{\circ} \mathrm{C}$. The distinct bright contrast along the GBs suggests the continuous thin $\mathrm{Nd}-$ rich phase layers. The average concentration of $\mathrm{Nd}$ along

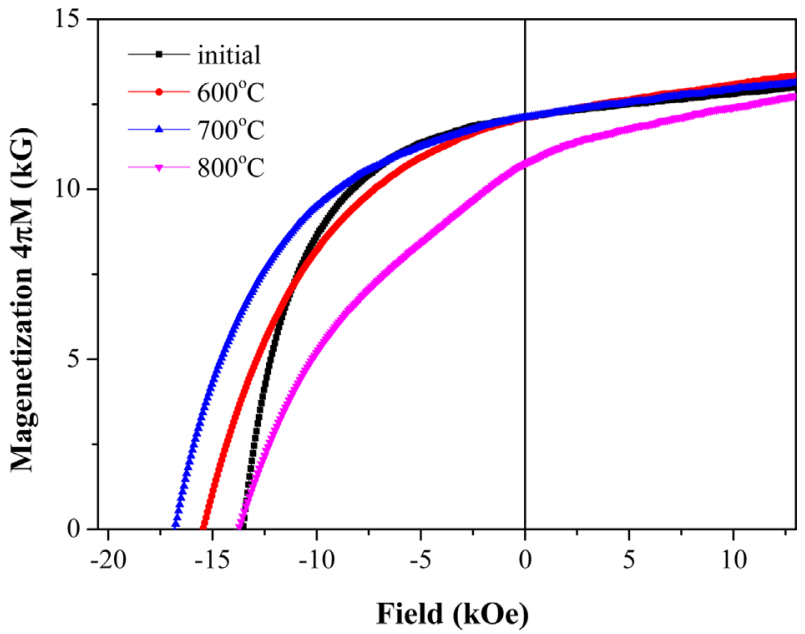

Fig. 5. (Color online) Demagnetization curves of the initial HDDR-treated powders and the HDDR-treated powders after GBDP with 6 wt.\% $\mathrm{Nd}-\mathrm{Cu}$ alloy at 600,700 and $800{ }^{\circ} \mathrm{C}$, respectively.

GBs after GBDP was higher (16.0 at.\%) than that (12.5 at.\%) of initial HDDR-treated powders. This increased fraction could be resulted from the diffusion of molten $\mathrm{Nd}-\mathrm{Cu}$ into the GBs. Furthermore, the concentration of $\mathrm{Cu}$ and $\mathrm{Ga}$ are higher along GB than that in the main phase. From the microstructural studies, it is clear that continuous thin $\mathrm{Nd}$-rich phase layer around main phases lead to a better separation of them and the clear and 
Table 1. Magnetic properties of the initial HDDR-treated powders and the HDDR-treated powders after GBDP with 6 wt.\% $\mathrm{Nd}-\mathrm{Cu}$ alloy at 600,700 and $800{ }^{\circ} \mathrm{C}$, respectively.

\begin{tabular}{cccc}
\hline \hline Samples & $\begin{array}{c}\text { Coercivity } \\
(\mathrm{kOe})\end{array}$ & $\begin{array}{c}\text { Remanence } \\
(\mathrm{kG})\end{array}$ & $\begin{array}{c}(\mathrm{BH})_{\max } \\
(\mathrm{MGOe})\end{array}$ \\
\hline Initial HDDR & 13.5 & 12.1 & 31.8 \\
GBDP at $600^{\circ} \mathrm{C}$ & 15.4 & 12.1 & 32 \\
$\mathrm{GBDP}$ at $700^{\circ} \mathrm{C}$ & 16.9 & 12.1 & 33 \\
$\mathrm{GBDP}$ at $800^{\circ} \mathrm{C}$ & 13.7 & 10.8 & 14 \\
\hline
\end{tabular}

smooth GBs. Moreover, the diffusion of $\mathrm{Cu}$ to the particles is beneficial to promote the wettability behavior and separation of main phase, leading to the homogeneous formation of Nd-rich phases, and results in high coercivity [22]. The microstructural modification after GBDP would be helpful to decrease the magnetic interactions among $\mathrm{Nd}_{2} \mathrm{Fe}_{14} \mathrm{~B}$ hard magnetic grains. Thus, any direct magnetic coupling of the $\mathrm{Nd}_{2} \mathrm{Fe}_{14} \mathrm{~B}$ grains could be reduced, which significantly improves the coercivity. The fine and uniform distribution of the $\mathrm{Nd}_{2} \mathrm{Fe}_{14} \mathrm{~B}$ grains and the modified GBs are important factors to improve the coercivity of $\mathrm{Nd}-\mathrm{Fe}-$ $B$ magnets.

Figure 5 shows the demagnetization curves of the HDDR-treated powders before and after GBDP with 6 wt. $\% \mathrm{Nd}-\mathrm{Cu}$ alloy at 600,700 and $800{ }^{\circ} \mathrm{C}$, respectively. The temperature for GBDP has a significant influence on the magnetic properties of HDDR-treated powders. The coercivity increases from $13.5 \mathrm{kOe}$ for the initial HDDRtreated powders to $16.9 \mathrm{kOe}$ for the powders after GBDP at $700{ }^{\circ} \mathrm{C}$ almost without remanence decrease (Table 1). The enhanced coercivity is attributed to the formation of the distinct GB phase which causes a weaker ferromagnetic interaction among the main grains. When the temperature of GBDP was further increased to $800{ }^{\circ} \mathrm{C}$, the coercivity is almost same as that of the initial HDDR-treated powders while the remanence also decreased. This irregular dependence of the magnetic properties of the HDDR-treated powders on the GBDP temperature can be attributed to not only the grain growth and the distribution of $\mathrm{Nd}$-rich phase through the GBs but also the residual hydrogenrelated disproportionation during GBDP.

\section{Conclusion}

HDDR-treated $\mathrm{Nd}-\mathrm{Fe}-\mathrm{B}$ powders were modified by grain boundary diffusion process with $\mathrm{Nd}-\mathrm{Cu}$ alloy. The temperature of GBDP with $\mathrm{Nd}-\mathrm{Cu}$ has a significant impact on the microstructures of HDDR-treated Nd-Fe$\mathrm{B}$ powders. The uniform distribution of $\mathrm{Nd}$-rich both at the triple junction and along the GBs for the sample after
GBDP at $700{ }^{\circ} \mathrm{C}$ gives rise to a remarkable increase of coercivity to $16.9 \mathrm{kOe}$ compared with $13.5 \mathrm{kOe}$ for the initial HDDR-treated powders. GBDP at $700{ }^{\circ} \mathrm{C}$ with $\mathrm{Nd}-\mathrm{Cu}$ alloy is not only effect to isolate the main phases but also to prevent the residual hydrogen induced phenomenon. The residual hydrogen-related degassing and disproportionation process also worked during GBDP at 600 and $700{ }^{\circ} \mathrm{C}$. When the temperature of GBDP was increased to $800{ }^{\circ} \mathrm{C}$, the grown grains and disproportionation process lead to weaken magnetic properties [18, 23].

\section{Acknowledgements}

This research was supported by a grant from the Fundamental R\&D Program for Core Technology of Materials funded by the Ministry of Knowledge Economy, Republic of Korea.

\section{References}

[1] J. F. Herbst, Rev. Mod. Phys. 63, 819 (1991).

[2] S. Sugimoto, J. Phys. D: Appl. Phys. 44, 064001 (2011).

[3] J. F. Herbst and W. B. Yelon. J. Appl. Phys. 57, 2343 (1985).

[4] H. R. Cha, J. H. Yu, Y. K. Baek, H. W. Kwon, T. H. Kim, C. W. Yang, T. S. Lim, Y. D. Kim, and J. G. Lee, Met. Mater. Int. 20, 909 (2014).

[5] H. R. Cha, J. H. Yu, Y. K. Baek, H. W. Kwon, Y. D. Kim, and J. G. Lee, J. Magn. 19, 49 (2014).

[6] W. F. Li, T. Ohkubo, and K. Hono, Appl. Phys. Lett. 93, 052505 (2008).

[7] R. Ramesh, G. Thomas, and B. M. Ma, J. Appl. Phys. 64, 6416 (1988).

[8] K. Uestuener, M. Katter, and W. Rodewald, IEEE Trans. Magn. 42, 2897 (2006).

[9] Y. Shinaba, T. J. Konno, K. Ishikawa, K. Hiraga, and M. Sagawa, J. Appl. Phys. 97, 053504 (2005).

[10] J. D. Livingston, J. Appl. Phys. 57, 4137 (1985).

[11] H. Sepehri-Amin, W. F. Li, T. Ohkubo, T. Nishiuchi, S. Hirosawa, and K. Hono, Acta Mater. 58, 1309 (2010).

[12] J. Fidler, J. Magn. Magn. Mater. 80, 48 (1989).

[13] H. Sepehri-Amin, T. Ohkubo, T. Nishiuchi, S. Hirosawa, and K. Hono, Scripta Mater. 63, 1124 (2010).

[14] J. J. Ni, T. Y. Ma, and M. Yan, J. Magn. Magn. Mater. 323, 2549 (2011).

[15] Z. Lin, J. Han, M. Xing, S. Liu, R. Wu, C. Wang, Y. Zhang, Y. Yang, and J. Yang, Appl. Phys. Lett. 100, 052409 (2012).

[16] M. Takezawa, Y. Nagashima, Y. Kimura, Y. Morimoto, J. Yamasaki, N. Nozawa, T. Nishiuchi, and S. Hirosawa, J. Appl. Phys. 111, 07A714 (2012).

[17] T. Nishiuchi, S. Hirosawa, M. Nakamura, M. Kakimoto, T. Kawabayashi, H. Araki, and Y. Shirai, IEEE Trans. 
Elec. Elec. Eng. 3, 390 (2008).

[18] M. A. Matin, H. W. Kwon, J. G. Lee, and J. H. Yu, IEEE Trans. Magn. 50, 1 (2014).

[19] W. F. Li, T. Ohkubo, K. Hono, T. Nishiuch, and S. Hirosawa, Appl. Phys. Lett. 93, 052505 (2008).

[20] H. Sepehri-Amin, D. Prabhu, M. Hayashi, T. Ohkubo, K. Hioki, A. Hattori, and K. Hono, Scripta Mater. 68, 167
(2013).

[21] M. Matin, H. W. Kwon, J. G. Lee, and J. H. Yu, J. Magn. 19, 106 (2014).

[22] S. Nishio, S. Sugimoto, R. Goto, M. Matsuura, and N. Tezuka, Mater. Trans. 50, 723 (2009).

[23] B. D. Cullity and C. D. Graham, Introduction to Magnetic Materials. Addison-Wesley, London (1972) pp. 360-362. 